\title{
Las Víctimas del Delito en los Tiempos del Olvido Una Reflexión Desde la Victimología en TORNo a la Reforma al Sistema PENAL EN COLOMBIA
}

\section{JULIO ANDRÉS SAMPEDRo ARRUBLA}

Director del Departamento de Derecho Procesal y del Centro de Estudios en Criminología y Victimología «Jorge Enrique Gutiérrez Anzola» de la Pontificia Universidad Javeriana, Bogotá-Colombia.

\section{Introducción}

T a reciente reforma al sistema penal colombiano no sólo ha servido para dar los primeros pasos en la implementación de un sistema de administración de justicia penal más humano, garantista y eficiente, sino que ha generado en Colombia una reflexión que nos habla del olvido y la marginación a que tradicionalmente se ha sometido a las víctimas del delito ${ }^{1}$, y ha develado la oposición cerrada y recalcitrante de sectores académicos y políticos al reconocimiento de que un futuro mejor está condicionado a que hagamos nuestra la causa de las victimas y entendamos de una vez por todas que, como escribe R. MATE, no es el recuerdo de los vencedores sino el de los vencidos el que crea la esperanza ${ }^{2}$.

En Colombia, con criterios tradicionales y excesivamente dogmáticos del derecho penal, se ha constituido una visión abstracta, con pretensiones de universalización y por tanto deshumanizada de la figura victimal: «todas las víctimas son ya la misma victima: la sociedad; y todas las victimizaciones típicas conculcan fundamentaly prioritariamente el orden penal del Estado» ${ }^{3}$. Los protagonistas en el drama criminal son despojados del conflicto y el proceso penal pasa a ser un escenario en el que solo tiene cabida el victimario y el Estado. Los conflictos que se presentan en la sociedad colombiana y que tienen alguna relevancia penal, han sido definidos en el sistema de justicia no en términos de las partes implicadas, sino más bien en términos de las regulaciones (legislación penal) y los requerimientos organizacionales del sistema mismo. Las partes directamente comprometidas en un conflicto pueden ejercer escasa influencia en el curso posterior de los eventos

\footnotetext{
1 El Derecho Penal, como sostiene Antonio Garcia-Pablos De Molina. El Redescubrimiento de la víctima: victimización secundaria y programas de reparación del daño. La denominada victimización terciaria (El penado como víctima del sistema legal), en Cuadernos de Derecho Judicial, La Victimología, Consejo General del Poder Judicial, Madrid, 1993, p. 306, parece hallarse sesgado y unilateralmente dirigido a la persona del infractor, relegando a la víctima a una posición marginal: al ámbito de la prevención social y del derecho civil sustantivo y procesal. El sistema legal, por ejemplo, define con toda precisión el estatus del inculpado, sin que dicho garantismo a favor del presunto responsable tenga como lógico correlato una preocupación semejante por los derechos del las víctimas.

2 Reyes Mate, La razón de los vencidos, Ed. Anthropos, Barcelona, 1991, p. 224

3 Cfr. Myriam Herrera Moreno, La Hora de la Víctima. Compendio de victimología, Publicaciones del Instituto de Criminología de la Universidad Complutense de Madrid, EDERSA, Madrid, 1996, p. 65.
} 
una vez que una materia ha sido definida como criminal y que ella, como tal, ha sido tomada por el sistema ${ }^{4}$.

En este orden de ideas, el delito se ha entendido como una vulneración a un bien (abstracción) protegido por el Estado; el conflicto que subyace al delito se disuelve, y las víctimas, marginadas, pierden por partida doble, primero, frente al delincuente, y segundo, al serles denegado el derecho a la plena participación en lo que podría haber sido uno de los encuentros rituales más importantes de su vida. Las víctimas han perdido su caso en manos del estado 5 . Paradójicamente, los sistemas penales que buscan su desarrollo en el marco de la democracia han fijado su atención más en la persona del victimario que en la de las víctimas y, preocupados por asegurar sus derechos a través de la implementación del llamado "garantismo penal»" han marginado a las víctimas, desconociendo que su presencia es fundamental para comprender integralmente el fenómeno social del delito ${ }^{7}$.

La evolución histórica del derecho penal y procesal penal en Colombia ha estado marcada por el olvido del $\operatorname{ser}^{8}$, por los derechos pendientes de los «vencidos», por ello el comienzo de un nuevo siglo invita ha hacer un corte y pensar en lo impensado, en la necesidad de la actualización de los derechos de las victimas, reconociendo que ellas son una realidad viviente que nos habla de las injusticias del pasado y nos obliga a tomarlas en cuenta como el camino obligado para construir una justicia ética; a pensar en una justicia diferente, sin venganza, que ponga su mirada en el sufrimiento de los inocentes y en la reparación del daño ocasionado voluntariamente.

Este planteamiento dio lugar, en parte, a que se emprendiera una reforma al sistema penal colombiano que no solo implementara un esquema de juzgamiento de tendencia acusatoria, sino que hiciera una apuesta por las víctimas del delito. Si bien es cierto no se puede afirmar que al final se hayan materializardo integralmente estas ideas, ellas sí fueron utilizadas en la defensa del proyecto de acto

4 Cfr. Louk Houlsman, El "Derecho de la Victima" a no ser subordinada a la dinámica de la Justicia Penal, en Cuadernos de Criminología N 7, Instituto de Criminología de Santiago, 1997, p. 100.

5 Cfr. Nils Christie. Los conflictos como pertenencia, en De los delitos y de la Víctimas, Editorial Ad-Hoc, Buenos Aires, 1992, pp. 162/163.

6 Cfr. Luigi Ferrajoli. Derecho y Razón. Teoría del garantismo penal, Editorial Trotta, Madrid, 1995; Derechos y Garantías. La Ley del más débil, Editorial Trotta, Madrid, 1999; Garantismo y Derecho Penal, en Democracia, Derechos Humanos, Derecho Internacional Humanitario, Compilador Miguel Rujana Quintero, Universidad Libre de Colombia, Facultad de Filosofía, Cátedra Gerardo Molina, Santafé de Bogotá D.C., 2000.

7 Como escribe Antonio GARCIA-PABLOS DE MOLINA. El Redescubrimiento de la víctima: victimización secundaria y programas de reparación del daño. Cit., p. 290, en el denominado Estado "social" de Derecho oscilan, paradójicamente, las actitudes reales hacia la víctima entre la compasión y la demagogia, la beneficencia y la descarada manipulación.

8 Cfr. Eugenio Raúl Zaffaroni, Alejandro Alagia, Alejandro Slokar, Derecho Penal. Parte General, EDiar, Buenos Aires, 2000, p. 341 y siguientes. 
legislativo y posteriormente en las discusiones que se presentaron en el seno de la Comisión Constitucional Redactora del Nuevo Código de Procedimiento Penal (hoy Ley 906 de 2004) .

En cuanto a las víctimas, el éxito de la reforma dependerá en buena parte de la posición que asuman los diferentes actores que intervienen en el Sistema Penal y de una verdadera postura a favor de las víctimas que se tenga a la hora de aplicar las normas que han sido aprobadas. De lo que se trata es de ver el mundo de manera invertida, con los ojos de las victimas que develan el sufrimiento humano y advierten que allí hay derechos que el sistema penal ha dejado pendientes y mientras no se atiendan nada impide que la barbarie del delito se repita.

Por ello, es necesario emprender una estrategia que permita repensar conceptos, como el de víctimas del delito, sobre los que se fundamenta el sistema penal para hacerlos más comprensivos a fin que posibiliten una justicia pluralista y más humana.

\section{2. ¿Quiénes son las del víctimas del delito?}

En la comprensión humana y pluralista que requiere la reforma es necesario que se nos permita, antes que nada, realizar una aproximación a un concepto de Víctimas del delito que sea comprensivo de todas aquellas personas y todos aquellos grupos que se ven afectados por el hecho criminal. Teniendo como punto de partida que la configuración del Estado de Derecho como social y democrático determina el marco general dentro del cual el ser humano puede desarrollar su personalidad, la afirmación en el sentido que la persona humana y su dignidad constituyen el principio y fin del Estado Social y Democrático de Derecho no es simple retórica sin ningún contenido; por el contrario, su reconocimiento conlleva importantes consecuencias para la dinámica de las relaciones sociales, pues supone la estructuración de una forma de organización política que tiene como razón de ser la creación de un medio idóneo para asegurar el desarrollo del ser humano en la vida en sociedad ${ }^{10}$. A partir de esta idea se puede señalar que el ordenamiento jurídico debe tener como centro de atención al hombre y estar identificado por su contenido social, lo que lleva a considerar que los ciudadanos y las autoridades deben asumir un papel activo, a la vez que un compromiso permanente en la pro-

9 Cfr. Reforma Constitucional de la Justicia Penal, Actas de la Comisión Preparatoria y Documentos de Trámite Legislativo, Corporación Excelencia en la Justicia, Bogotá D.C. 2002; Tomo II, Texto del Acto Legislativo 03 de 2002 y Documentos de Trámite, Corporaciuón Excelencia en la Justicia, Bogotá D.C., 2003; AnTEProyeCto de Código de Procedimiento Penal, en desarrollo del Acto Legislativo 03 de 2002, Jaime Enrique Granados Peña, Julio Andrés Sampedro Arrubla, Juan David Riveros Barragan, Mildred Hartmann Arboleda, Editorial Legis, Bogotá D.C., 2003.

10 Gregorio Peces-Barba, Los Valores Superiores, Editorial Tecnos, $1^{\text {a }}$ reimpresión, Madrid, 1986, pág. 63. 
moción de los derechos fundamentales, en la superación de la idea de Estado de Derecho como expresión de la legalidad abstracta, y en la consideración del ser humano como un individuo de carne y hueso, individual o colectivo, sujeto de derechos y responsable frente a sí mismo y a sus semejantes ${ }^{11}$.

Al determinar el contenido y la orientación del ordenamiento jurídico el Estado Social y Democrático de Derecho permite superar las concepciones tradicionales, al tiempo que realizar un esfuerzo en la reelaboración de conceptos básicos con el propósito de asegurar las condiciones indispensables para que las personas tengan una vida digna que les permita su desarrollo como seres humanos. Por ello, la reducción de la persona a un simple objeto o categoría, los tratos crueles, inhumanos o degradantes, los comportamientos que se muestren indiferentes ante la muerte o las necesidades y expectativas de quienes se encuentran en situación de inferioridad, o produzcan su marginación, son conductas que desconocen los valores sobre los que se fundamenta este modelo, e impiden su desarrollo.

Expresión importante de esta situación se concreta en el tratamiento que reciben las víctimas del delito, quienes debieran ocupar un lugar principal en la lista de prioridades del Estado, y sin embargo éste las ha neutralizado y, en el mejor de los casos, solo tiene para ellas sentimientos de pesar sin obtener la atención que sus necesidades requieren. Reducidas a la categoría abstracta de sujeto pasivo del delito o titular del bien jurídico protegido con la norma, han quedado por fuera otras personas o grupos, que por no haber sufrido un daño directo con el delito, no son consideradas como víctimas a pesar de padecer las consecuencias nocivas del hecho criminal ${ }^{12}$.

Desde una dimensión ético-filosófica, R. Mate ${ }^{13}$ recoge en tres puntos algunas reflexiones, con referencia particular al terrorismo, que nos pueden servir para puntualizar las bases de un concepto democrático y pluralista de víctimas en el sistema penal.

En primer lugar, las víctimas son siempre inocentes, con lo que el verdugo es culpable de una injusticia, condición que no perderá jamás aunque acabe pagando las consecuencias legales de sus actos.

En Colombia ha sido frecuente, especialmente en algunos sectores de la opinión, considerar como víctimas de las desigualdades sociales a los guerrilleros

11 Ana Mesutti, El tiempo como pena y otros escritos, Editorial Pontificia Universidad Javeriana, Colección Criminología y Victimología No 2, Santafé de Bogotá, 1998, pág. 115.

12 Antonio Garcia-Pablos De Molina, El redescubrimiento de la Víctima: victimización secundaria y programas de reparación del daño. La denominada victimización terciaria (el penado como víctima del sistema legal), en Cuadernos de Derecho Judicial, La Victimología, Consejo General del Poder Judicial, Madrid, 1993, pág. 290.

13 Reyes Mate, ¿Pero quiénes son las víctimas?, El Pais, Madrid, 18 de enero de 2001. 
que combaten contra la sociedad desarmada; o a los miembros de grupos de «autodefensa», quienes para justificar sus acciones de barbarie, aducen haber sido objetivo de la violencia guerrillera ${ }^{14}$. Las víctimas no pueden confundirse con el sufrimiento, por eso los verdugos aunque también sufran, no son víctimas porque no son inocentes.

En segundo lugar, las víctimas tienen voz propia y no debemos permitir que nadie la sustituya, ni la olvide. Esa voz habla de la gratuidad de la violencia del verdugo, nada la puede explicar, ni justificar el sufrimiento de las víctimas. Como escribe J. C. Melich, pensar que el sufrimiento del otro pueda ser útil para algo o para alguien es un supremo acto de barbarie ${ }^{15}$. El acto terrorista no aporta nada nuevo, no desvela ninguna razón oculta que ayude a comprender su causa. Es el mal por el mal. Si se compara en Colombia los diferentes discursos de los llamados «Grupos Armados» se encuentran más puntos de convergencia que de divergencia. Todos pretenden justificar su barbarie mediante la lucha violenta por la reivindicación de los derechos de una población que desarmada e indefensa se ha convertido en el blanco de sus atroces ataques ${ }^{16}$.

En tercer lugar las víctimas no solo desvelan la maldad radical de la acción terrorista, sino que además introducen un elemento nuevo en la reflexión política que altera los planteamientos políticos relacionados directa o indirectamente no sólo con los verdugos, sino también con los afines. La novedad introducida en el debate político por las víctimas es su propia existencia, una novedad que aparece con mayor fuerza entre las víctimas inocentes carentes de todo discurso propio.

La presencia de esas víctimas inocentes (expresada metafóricamente por R. MATE en la «mirada de la víctima»), no solo son un problema a resolver, sino el paso obligado de cualquier solución. Ellas tienen la clave de la posible integración de la parte violenta en la futura comunidad política reconciliada.

Estas ideas permiten introducirnos en los planteamientos de la victimología ${ }^{17} \mathrm{y}$ también de la criminología a fin de estructurar un nuevo concepto de víctimas en relación con el Derecho Penal y el Procesal.

14 Cfr. Scott Wilson, Entrevista con Carlos Castaño, Jefe de las Autodefensas Unidas de Colombia, marzo 12 de 2001,www.colombialibre.org/reportajes/entrevistas_report3_espanol.htm

15 Joan-Carles Melich, Totalitarismo y Fecundidad. La filosofía frente a Auschwitz, Ob. Cit., p. 91.

16 El daño, como escribe Carlos Thiebaut, De la Tolerancia, Ob. Cit., p. 21, es innecesario por partida doble: en primer lugar porque podemos impedirlo; en segundo lugar, porque debiéramos, de forma moralmente necesaria, impedirlo.

${ }^{17}$ El punto de partida de la actual Victimología puede situarse en el I Symposium Internacional sobre Victimología celebrado en Jerusalén en 1973; allí se definió como el estudio científico de las víctimas. Sin embargo el objeto de estudio de la Victimología no se limita solo a la víctima; como lo dice L. Rodriguez Manzanera debe estudiarse también su conducta, aislada y en relación con la conducta criminal (cuando la hay) así como el fenómeno victimal general y en conjunto, con las caracteristicas que lo conforman. Victimología. Estudio de la Víctima, Editorial Porrúa, Tercera edición, México, 1996, pág. 33. 
El Derecho Penal opera con un concepto limitado de victimas del delito, entendiendo que la víctima es el titular del bien jurídico protegido o sujeto pasivo de la infracción; a su lado se encuentran los perjudicados con el delito, es decir, aquellos que se ven directa e indirectamente afectados por el delito, pero que no son sujetos pasivos ${ }^{18}$. Como escriben G. Quintero Olivares, F. Morales Prats y J.M. Prats Canut:

«El concepto de sujeto pasivo del delito ocupa el otro extremo de las relación delictiva. No bay que confundir, no obstante, las categorías de sujeto pasivo y de perjudicado, aunque con frecuencia ambas pueden resumirse en una misma persona. Sujeto pasivo es la persona titular del bien jurídico ofendido. Perjudicado es quien sufre económica y moralmente las consecuencias del delito... ${ }^{19}$

Esta distinción entre víctima y perjudicado tiene una especial importancia para la dogmática jurídico penal que se concreta, por un lado, en que le permite al legislador establecer la gravedad del ilícito en la medida en que la esencialidad del bien y la intensidad de la sanción se determinarán a la vista de la relación entre bien y titular del mismo. De otro lado, la existencia de una víctima legalmente capaz de actuar impide actuar a los perjudicados en ejercicio de la acción civil en el proceso penal ${ }^{20}$.

Por su parte, la Victimología busca estructurar un concepto más amplio de víctimas, el cual, respetando los postulados básicos del Estado Social y Democrático de Derecho, garantice la atención integral de todos los protagonistas del suceso criminal y, sin desconocer los derechos fundamentales de los victimarios, permita adoptar una opción preferencial por las víctimas, especialmente en el Proceso penal, el cual, como afirma G. P. FLETCHER, se ha convertido en el más significativo símbolo de las agresiones que puede infligir una comunidad ${ }^{21}$.

18 En el Derecho Penal, escriben José Adolfo Reyes Calderon/Rosario Leon-Dell, Victimología, Reyes-León Editor, Guatemala, 1997, p. 243, «se estudia la víctima en forma muy superficial, refiriéndose al sujeto pasivo como un simple elemento del tipo penal. Normalmente, en los tratados referidos a la parte general casi no se le menciona y en la parte especial solamente en algunos delitos. La ley penal pone énfasis en los autores de los delitos y en la conducta de los mismos...»; por su parte afirma ABELARdo Rivera Llano, La Victimología ¿Un problema criminológico?, Jurídica Radar, Bogotá, 1997, p. 107, «que hasta hace pocas décadas los mismos criminólogos habian desatendido, prácticamente, esta problemática y aun los penalistas consideraban, al margen de las especificas circunstancias de atenuación o exención de responsabilidad y de pena, dogmáticamente irrelevante la figura del sujeto pasivo, ante la convicción de que todos los elementos del tipo debian ser leidos con referencia exclusiva al sujeto activo y al bien jurídico tutelado, dado que la discusión político-criminal estaba orientada, en la postura positivista, exclusivamente hacia el autor»

19 Gonzalo Quintero Olivares, Fermín Morales Prats Y José Miguel Prats Canut, Manual de Derecho Penal Parte General, Editorial Aranzadi, Navarra, 1999, p. 648.

${ }^{20}$ Cfr. Ferrando Mantovani, Diritto Penale Parte Generale, CEDAM-PADOVA, Padova, 1979, p. 210 y ss.; Joan J. Queralt, Víctimas y garantías: algunos cabos sueltos a propósito del Proyecto Alternativo de reparación, en Anuario de Derecho Penal y Ciencias Penales, Ministerio de Justicia e Interior, Tomo XLIX, Fascículo I, Madrid, enero-abril de 1996, p. 142.

${ }^{21}$ George P. Fletcher, Las Víctimas ante el Jurado, trad. Juan José Medina Ariza y Antonio Muñoz Aunión, Ed. tirant lo blanch, Valencia, 1997, p. 323 y ss. 
El punto de partida de la actual Victimología se sitúa en el I Symposium Internacional celebrado en Jerusalén en 1973; allí fue definida como el estudio científico de las víctimas. Sin embargo, hoy su objeto de estudio se ha ampliado y se puede afirmar que se ocupa, también, de su conducta, aislada y en relación con la conducta criminal (cuando la hay) así como el fenómeno victimal general y en conjunto, con las características que lo conforman ${ }^{22}$. Persigue, como lo señala A. GARCIA-PABLOS, una redefinición del status de víctima y de las relaciones de esta con el delincuente, el sistema legal, la sociedad, y los poderes públicos, y además, como lo hemos señalado, penetrar en el campo de los derechos humanos para dar respuestas eficaces y válidas a todas las víctimas ${ }^{23}$.

Gracias a la influencia de la Victimología, se ha ido superando el concepto individual de víctima, para dar paso a una concepción amplia, comprensiva no solo del sujeto pasivo del delito sino de otras personas naturales o jurídicas, que aunque no estén individualizadas, pueden haber sufrido daños como consecuencia de la infracción.

En este contexto, resulta de particular importancia la Declaración de Justicia y Asistencia para las Victimas elaborada por la Sociedad Internacional de Victimología ${ }^{24}$ y presentada en el Congreso Internacional de las Naciones Unidas de 1985, documento en el cual se deja claro que la víctima es la persona (entendiendo por tal entidades legales, organizaciones, asociaciones, comunidades, el Estado o la sociedad en un todo), que haya sufrido una lesión o daño físico o mental, una pérdida o daño material, o cualquier otro perjuicio social como resultado de una acción que sea constitutiva de un delito, crimen internacional, violación a los derechos humanos reconocidos internacionalmente, o abuso de poder.

De acuerdo con lo planteado hasta el momento, es posible estructurar algunos criterios que consideramos esenciales para precisar quienes son las víctimas el delito:

En primer lugar, en la noción de víctimas del delito se admiten varios niveles: incluye al sujeto pasivo, pero lo supera permitiendo considerar como tales a los

22 Luis Rodriguez Manzanera, Victimología. Estudio de la Víctima, Editorial Porrúa, Tercera edición, México, 1996, pág. 33

23 Antonio Garcia-Pablos De Molina, Criminología. Una introducción a sus fundamentos teóricos para juristas, Tercera Edición, Editorial Tirant Lo Blanch, Valencia, 1996, pág. 41.

${ }^{24}$ La Sociedad Internacional de Victimología fue creada en el III Simposio de Victimología celebrado en Münster (Westfalia) en el año 1979. Esta organiza, cada tres años, un symposium en el cual se reúnen profesionales de diferentes disciplinas que han contribuido al desarrollo de esta disciplina. A. BERISTAIN, quien participó en su fundación, dice sobre sus objetivos: «Reunidos en sesión extraordinaria, formulamos con rigor científico las metas de esta sociedad. Pretende no solamente la hominización y/o disminución de la severidad de las penas con que tradicionalmente la comunidad responde a los delincuentes, sino además un cambio cualitativo (más que cuantitativo) que aboque una redefinición legal y práctica en profundidad de toda institución policial, judicial, penitenciaria. Su alfa y omega será la víctima, no el criminal». De los Delitos y de las Penal desde el País Vasco, Editorial Dykinson, Madrid, 1998, Pág. 217. 
perjudicados, directos e indirectos, con la infracción. Igualmente abarca la victimación producida por conductas que afectan a la sociedad en su conjunto, que son clasificadas como "delitos sin víctimas", cuando en realidad son comportamientos ilícitos que aunque no tienen una víctima personificada, dañan grupos o comunidades en su conjunto, cuyos autores, por diversas razones, probablemente nunca serán juzgados, tal como ha sucedido en Colombia con la financiación de campañas políticas por el narcotráfico, o con el desastre ecológico que se ha producido como consecuencia de los permanentes atentados terroristas realizados por la guerrilla en contra de los oleoductos ${ }^{25}$.

En segundo lugar, se debe resaltar que el concepto de víctimas no se limita a las personas naturales o físicas, sino que abarca a las personas jurídicas e incluye otros grupos que pueden ser victimizados, superando, de esta manera, la critica formulada a la victimología en el sentido que, por su origen positivista, deja por fuera del concepto de víctimas a las personas jurídicas, colectivos y asociaciones ${ }^{26}$.

En tercer lugar, se debe tener en cuenta que para ser víctima no es necesario que la persona se sienta como tal, como sucede en muchos delitos económicos en los cuales el sujeto puede no tener conciencia del engaño sufrido ${ }^{27}$.

En cuarto lugar, es preciso poner de presente que la víctima del delito es toda persona que sufre un daño como consecuencia de la comisión de un delito, con independencia de la relación que exista con el victimario y de la influencia que su conducta haya tenido en la producción del hecho, pues hay quienes sostienen, basándose en la interacción que existe entre la víctima y el victimario, la coresponsabilidad de la víctima en la generación del delito ${ }^{28}$, y afirman, que el delito está también determinado por la propia víctima ya que existen características intrínsecas (antropológicas, psicológicas o sociales) en su comportamiento que la predisponen a convertirse en víctima ${ }^{29}$.

De lo expuesto, cabe afirmar una postura por una concepción amplia de las víctimas del delito que armonice los valores esenciales del modelo de Estado

\footnotetext{
25 La Defensoría del Pueblo en Colombia presentó un informe sobre la grave problemática ambiental, de vulneración del Derecho Internacional Humanitario, y victimación que implica un número creciente de 562 voladuras de los oleoductos colombianos examinadas en un período de 10 años (1986 -1996). Entre muchas cosas se afirma que en el área de influencia directa de una voladura (donde hay derrame de crudo), el horizonte orgánico de dichos suelos es destruido completamente (pues es removido junto con el material vegetal) y los horizontes minerales son drásticamente afectados, por lo cual los organismos vivos que tienen un papel fundamental en el proceso de formación del suelo desaparecen, quedando así impedido dicho proceso.

26 Juan Bustos Ramirez. Helena Larrauri, Victimología : Presente y Futuro, Editorial Temis, Segunda Edición, Santafé de Bogotá, 1993, pág. 12.

27 Andrés Martinez Arrieta, La Victima en el Proceso penal (I), en Actualidad penal, No 4, enero de 1990, pág. 45.

28 M.M. Correra y D. Riponti hacen depender la condición de víctima a que el daño lo sufra "sin su culpa" La Vittima nel Sistema Italiano della Giustizia Penale, Casa editrice Dott, Padova, 1990, pág. 4.

29 M.M. Correra y D. Riponti La Vittima nel Sistema Italiano della Giustizia Penale, Ob. Cit., pág. 13.
} 
Social y Democrático de Derecho, constituye el presupuesto indispensable para una reformulación del modelo tradicional del proceso penal, tarea que, como se ha dejado planteado, debe emprenderse desde la Victimología orientando e influyendo cada día con más fuerza la dirección y el contenido del derecho penal y procesal penal, así como de la política criminal, tanto en el ámbito de las regulaciones internacionales como en el de las legislaciones nacionales.

Es de resaltar cómo la problemática de las víctimas también ha sido preocupación permanente de la Organización de las Naciones Unidas; la Resolución 40/34 sobre los principios básicos de justicia para las víctimas del crimen y de abuso de poder es una muestra de ello. Esta fue adoptada por unanimidad en Milán en 1985 y, según sostiene F. DÜNKEL, constituye uno de los éxitos mas significativos de la Victimología ${ }^{30}$.

En esta resolución se plantean tres hipótesis para definir a las víctimas en un sentido amplio. Las dos primeras referentes a las víctimas del delito (numerales 1 y 2 del apartado A) y otra a las víctimas del abuso de poder (Apartado B).

Sobre las primeras estableció:

«1. Se entenderá por "victimas", las personas que, individual o Colectivamente, hayan sufrido daños, incluidos lesiones físicas o mentales, sufrimiento emocional, pérdida financiera o menoscabo sustancial de sus derechos fundamentales, como consecuencia de acciones u omisiones que violen la legislación penal vigente en los Estados Miembros, incluida la que proscribe el abuso de poder». «2. Podrá considerarse "victima" a una persona con arreglo a la Declaración independientemente de que se identifique, aprehenda, enjuicie o condene al perpetrador e independientemente de la relación familiar entre el perpetrador y la víctima. En la expresión "víctima" se incluye además, en su caso, a los familiares o dependientes inmediatos de la víctima directa y a las personas que hayan sufrido daños al intervenir para asistir a la víctima en peligro o para prevenir la victimización».

En cuanto a las víctimas del Abuso de Poder, dijo: "Se entenderá por "víctimas" las personas que, individual o colectivamente, hayan sufrido daños, incluidos lesiones físicas o mentales, sufrimiento emocional, pérdida financiera o menoscabo sustancial de sus derechos fundamentales, como consecuencia de

30 Frieder Dünkel, Fundamentos Victimologicos Generales de la Relación entre víctima y autor en el derecho penal, en Beristain/De la Cuesta, Victimología, Universidad del País Vasco, , pág. 161. 
acciones u omisiones que no lleguen a constituir violaciones del derecho penal nacional, pero violen normas internacionalmente reconocidas relativas a los derechos bumanos».

A partir de esta definición, la Organización de las Naciones Unidas deja planteadas dos ideas que nos interesa resaltar para una mejor y mas amplia comprensión del concepto de las víctimas del delito. La primera, según la cual, la consideración de "víctima" a una persona podrá realizarse con independencia, por una parte, de que se identifique, aprehenda, enjuicie o condene a los victimarios, y por la otra, de la relación familiar entre el perpetrador y la víctima. Esta idea resulta de particular importancia si se tiene en cuenta que hay quienes piensan que de la misma forma en que no se puede tener como autor del delito al imputado hasta que exista una sentencia que así lo declare, tampoco es posible afirmar la condición de víctima hasta la misma oportunidad procesal ${ }^{31}$.

La segunda, que en el concepto se incluye a los familiares o dependientes inmediatos de la víctima directa y a las personas que hayan sufrido daños al intervenir para asistir a la víctima en peligro o para prevenir la victimación, dejando en claro que, además de los perjudicados directos con la comisión del hecho criminal existen otros, indirectos, que están cobijados que también deben ser tenidos en cuenta a la hora de atender sus necesidades y expectativas.

Este concepto adquiere gran relevancia frente a otros documentos relativos a las víctimas producidos por las Naciones Unidas, en los cuales se pone de presente una opción preferencial por las víctimas en el sistema de justicia penal. Veamos:

En el Octavo Congreso de las Naciones Unidas sobre prevención del Delito y Tratamiento del Delincuente, celebrado en la Habana (Cuba) del 27 de agosto al 7 de septiembre de 1990, se dictaron las Directrices sobre la Función de los Fiscales. En este documento se dijo claramente que el cargo de Fiscal debe estar estrictamente separado de las funciones judiciales (num. 10) y dentro de las funciones propias que debe desempeñar en el marco del procedimiento penal (num. 13, b y c) se manifestó que en cumplimiento de sus obligaciones, los fiscales:

b) Protegerán el interés público, actuaran con objetividad, tendrán debidamente en cuenta la situación del sospechoso y de la víctima.

d) Considerarán las opiniones e inquietudes de las víctimas cuando se vean afectados sus intereses personales y aseguraran que se informe a las víctimas de sus derechos

31 Así se dejó plasmado en las conclusiones del XVII Congreso Argentino de Derecho Procesal, realizado en Santiago del Estero en 1993, citado por Pedro J. Bertolino en La Víctima en el Proceso Penal. Su régimen legal en Argentina, Bolivia, Brasil, Chile, Paraguay, Uruguay, Ediciones Depalma, Buenos Aires, 1997, pág. 17. 
con arreglo a la Declaración sobre los Principios Fundamentales de Justicia para las

Victimas de Delitos y del Abuso del Poder.

En la Declaración de Viena sobre la delincuencia y la justicia: frente a los retos del siglo XXI, producida en el Décimo Congreso de las Naciones Unidas sobre Prevención del Delito y Tratamiento del Delincuente realizado en Viena del 10 al 17 de abril de 2000. En ella se reconoce que las estrategias de prevención del delito en los planos nacional, regional y local deben abordar las causas profundas y los factores de riesgo relacionados con la victimación (num. 25), y alienta a la elaboración de políticas que respeten los derechos, necesidades e intereses de las víctimas, las comunidades y demás partes interesadas (num. 28).

Según se consigna en el Informe ${ }^{32}$ del Congreso, en su primera sesión plenaria, celebrada el 10 de abril, se asignó a la Comisión I el tema: Delincuentes y víctimas: responsabilidad y equidad en el proceso de justicia penal. Para el examen de este tema se tuvo en cuenta el documento de trabajo preparado por la Secretaria ${ }^{33}$. En él se hizo un análisis de temas como equidad para las víctimas (con mención expresa al catálogo de derechos de las víctimas en los procesos penales); a los conflictos de interés entre los delincuentes y las víctimas; a la relación de la víctima con el Estado y el reforzamiento del Ministerio Fiscal cuando las victimas actúan como asistentes en la acusación; y a la justicia restaurativa como modelo alternativo a la justicia penal.

Se puede afirmar que la atención a las víctimas y el reforzamiento de su posición en los sistemas de justicia penal es una posición adoptada en consenso internacional que obliga a los Estados a tomar medidas para adaptar sus legislaciones en busca de un reconocimiento contundente de las víctimas como protagonistas del delito y del consecuente proceso; tanto el modelo de Estado Social y Democrático de derecho y los planteamientos surgidos desde la Victimología aportan importantes criterios, que nos interesa resaltar, para alcanzar un concepto amplio y pluralista de víctimas del delito:

En primer lugar, la necesidad de superar la identificación de las víctimas del delito con el sujeto pasivo del mismo. Las definiciones de víctimas del delito que se proponen desde la Victimología y que son acogidas en el ámbito internacional, superan la consideración individual de la víctima y, además del titular del bien jurídico protegido, alcanzan a otros muchos perjudicados, directos e indirectos, que sufren las consecuencias de la violación de la norma.

En segundo lugar, las víctimas del delito pueden ser personas naturales como jurídicas, grupos, o comunidades afectadas por la comisión del ilícito.

${ }^{32}$ Documento A/CONF.187/15

${ }^{33}$ Documento A/CONF. $187 / 8$ 
En tercer lugar, aunque creemos que el fenómeno delictivo no puede entenderse sin la presencia de las víctimas, la condición se adquiere por el hecho mismo del daño ocasionado con la comisión del delito, sin importar la relación de estas con el victimario (s), y/o la influencia que su conducta pueda tener en la comisión del delito.

En cuarto lugar, para ser víctima no es necesario que la persona se sienta como tal, así sucede en muchos delitos en los cuales puede no tener conciencia de su victimación, de tal manera que se abre un campo importante para el ejercicio de una labor pedagógica en la cual desde el proceso penal quienes en él intervienen tienen un papel fundamental que desempeñar.

En quinto lugar, quien sufre el daño, directa o indirectamente, como consecuencia del delito debe ser considerado víctima con independencia de si es o no identificado, acusado o declarado judicialmente culpable, el o los victimarios. En este sentido no nos parece posible que se pueda hablar de "las presuntas víctimas" en el mismo sentido en que se habla del "presunto delincuente".

A partir de estos criterios, debe entenderse por víctimas del delito a los titulares del bien jurídico protegido con la norma, pero no exclusivamente ellos, pues hay otras personas o grupos que se ven perjudicadas directa o indirectamente con la conducta criminal y que tienen los mismos derechos de quienes han sufrido la agresión directa para ser atendidos en sus necesidades y expectativas con independencia de la relación que tenga con su (sus) victimario (s) y del enjuiciamiento, acusación o condena que se produzca en su contra. En concreto, dentro de las víctimas del delito y para efectos procesales, se debe incluir: el sujeto pasivo de la infracción entendido como aquella persona (s) sobre la cual recae la acción del delincuente; los perjudicados directos que son quienes, sin ser los titulares del bien jurídico protegido, reciben directamente los efectos del delito como los familiares de la persona asesinada; y los perjudicados indirectos, quienes sin ser titulares del bien jurídico ni perjudicados directos, deben soportar las consecuencias indirectas del delito, tales como los familiares o dependientes inmediatos del sujeto pasivo que sufran daños al intervenir para asistir a la víctima en peligro o para prevenir la victimación.

Este concepto, punto de partida para la reformulación del Proceso Penal, permite considerar a las víctimas del delito como sujetos de derechos y obligaciones que merecen respeto, y examinar el proceso desde una perspectiva diferente, más humana, para lograr que se convierta en un instrumento para la garantía y efectividad de la libertad, la igualdad, la justicia, y la obtención y 
mantenimiento de la paz social. El fenómeno criminal, como escribe E. NEUMAN no puede explicarse sin la presencia de las víctimas: "Será preciso su análisis e investigación, que revelan en múltiples delitos, la cada vez más tangible interacción con el delincuente, a punto tal que sin ella no puede comprenderse debidamente la conducta de ester) ${ }^{34}$.

\section{El Nuevo Código de Procedimiento Penal (ley 906 de 2004): ¿Es en realidad una reconstrucción victimologica del sistema penal?}

La filosofía, el derecho penal, la criminología, los instrumentos internacionales para la protección y desarrollo de los derechos humanos y la victimología, proporcionan las coordenadas fundamentales para la reformulación del proceso, un proceso más humano que, a través de la consagración especifica y la protección eficaz de los derechos humanos de las víctimas del delito, brinde un espacio apropiado para escuchar el clamor de las víctimas por la verdad y la justicia, especialmente en su faceta restaurativa. Cabe entonces preguntarse si en Colombia luego de la aprobación del Acto Legislativo 03 de 2002 y con su implementación legislativa plasmada en la Ley 906 de 2004, nuevo Código de Procedimiento Penal, se ha logrado una verdadera apuesta por las víctimas, una reconstrucción victimológica del Sistema Penal, o por el contrario no es más que una regulación legal en la que existen gran cantidad de referencias a las victimas pero carente de contenido victimológico. A buscar la respuesta a este interrogante dedicaremos nuestra atención es este apartado.

La estructuración de un concepto amplio de víctimas del delito para el proceso penal que supere la consideración limitada del derecho tradicional sirve como punto de partida para determinar hasta donde se ha llegado en Colombia con la modificación al sistema penal en busca de un proceso penal más humano. Es muy difícil alcanzar una comprensión más humana e integral del delito sin tener presente a las víctimas; por ello la necesidad de estructurar un concepto que se nutra de las ideas formuladas desde la victimología y el derecho internacional, en busca de una mayor coherencia con los postulados propios del modelo de Estado Social y democrático de Derecho que contribuya al desarrollo efectivo de los derechos humanos, de los victimarios y preferentemente de las victimas, en el proceso penal ${ }^{35}$.

${ }^{34}$ Elías Neuman. Victimología. El rol de la víctima en los delitos convencionales y no convencionales, Ed. Cárdenas Editor, Mexico, 1992, p. 43.

35 Cfr. Jaime Miguel Peris Riera, Aproximación a la Victimología. Su justificación frente a la Criminología, en Cuadernos de Política Criminal $\mathrm{N}^{\circ}$ 34, Instituto Universitario de Criminología, Universidad Complutense de Madrid, Editorial EDERSA, Madrid, 1984, p. 101. 
El Fiscal General de la Nación convocó una Comisión Técnica Interinstitucional con el fin de estudiar los problemas del sistema penal y proponer soluciones ${ }^{36}$; del trabajo de esta comisión surgió un proyecto de reforma constitucional que fue presentado al Congreso de la República el 26 de abril de 2002 y aprobado en forma definitiva por el Acto Legislativo 03 del 2002. Esta modificación tiene dos pilares esenciales en los cuales se fundamenta: por una parte la implementación de un sistema acusatorio que consulte los estándares internacionales para eficacia y garantía de la persecución de los delitos y el juzgamiento de personas; y por la otra, una apuesta por la protección y atención integral a las víctimas del delito, entendiendo que sólo aportando respuestas efectivas a sus expectativas es posible hacer justicia como paso previo para alcanzar y fortalecer la paz.

El trabajo más intenso se presenta con el desarrollo legislativo ${ }^{37}$ que exige la reforma constitucional, para ello se conformó, de acuerdo con el artículo transitorio 4, una Comisión, presidida por el Fiscal General de la Nación e integrada por el Ministro de Justicia y del Derecho, el Procurador General de la Nación, el Presidente de la Sala Penal de la Corte Suprema de Justicia, el Defensor del Pueblo, el Presidente del Consejo Superior de la Judicatura, tres Representantes a la Cámara y tres Senadores de las Comisiones Primeras, y tres representantes de la academia designados de común acuerdo por el Gobierno y el Fiscal General, la cual tuvo como misión elaborar y presentar al Congreso de la República a más tardar el 20 de julio de 2003 los proyectos de ley para adoptar el nuevo sistema, entre ellos el Código de Procedimiento Penal.

En este orden de ideas, se preparó un Anteproyecto de Código de Procedimiento Penal que sirvió de base a la Comisión Constitucional Redactora para adelantar sus discusiones durante el primer semestre de 2003 y presentar por conducto

${ }^{36}$ Esta Comisión estuvo integrada por: Luis CAMILO Osorio, Fiscal General de la Nación; GustaVo Morales Marin, Vicefiscal General de la Nación; Gustavo Gomez Velásquez Asesor del Fiscal General y Julio AndRés Sampedro Arrubla; Felipe Pinzon Londoño, delegado del Ministerio de Justicia; Fernando Coral Villota, Presidente del Consejo Superior de la Judicatura; Dora Cifuentes Ramírez, delegada de la Procuraduría General de la Nación; Juan Jaramillo Perez Y Karin Kuhfeldt Salazar, delegados de la Defensoría del Pueblo; Jaime E. Granados Peña Y Juan David Riveros Barragán, de la Corporación Excelencia en la Justicia; y Gustavo Salazar TrujlLlo, Representante de la Asociación de Universidades (ASCUN). A pesar de la oposición manifestada por la Sala Penal de la Corte Suprema de Justicia durante el trámite legislativo, dos de sus magistrados participaron esporádicamente en la comisión: Fernando Arboleda Ripoll y Alvaro Orlando Perez Pinzon, este último en su calidad de Presidente de la sala. Cfr. Reforma Constitucional de la Justicia Penal. Actas de la Comisión Preparatoria y Documentos de Trámite Legislativo, Tomo I, Corporación Excelencia en la Justicia, Bogotá D.C., 2002.

37 El propio Acto Legislativo contempla un régimen de transición gradual y sucesivo, iniciando con la integración de una Comisión, presidida por el Fiscal General de la Nación, que sen encargará de realizar los ajustes que requiera el Código Penal y elaborar un Código de Procedimiento Penal, la Ley Estatutaria de Administración de Justicia, la Ley Estatutaria de Habeas Corpus y el Estatuto Orgánico de la Fiscalia. Estos cuerpos legislativos deberán ser presentados al Congreso de la República a más tardar el 20 de julio de 2003 y este tendrá como plazo para aprobarlos hasta el 20 de junio de 2004. La implementación del nuevo sistema debe iniciarse el 1 de enero de 2005 en forma gradual y sucesiva hasta el 2008 cuando deberá quedar totalmente instaurado. 
del Fiscal General de la Nación el Proyecto de Código de Procedimiento Penal al Congreso de la República en donde hoy se encuentra en trámite. Veamos como se estructuró el concepto de víctimas del delito:

Es necesario advertir que la reforma constitucional no limita el concepto de víctimas al solo sujeto pasivo del delito o perjudicado directo con la conducta criminal, como tradicionalmente se ha hecho en el sistema penal colombiano, en el entendido que la conducta del delincuente produce un número plural de víctimas que deben ser atendidas en sus diversas pretensiones dentro del proceso; algunas pretenderán el acceso a la verdad, otras la reparación, otras una indemnización, etc., lo que ocurre es que el sistema penal debe entender que todo delito supone un conflicto humano que debe ser resuelto y para ello debe contar con los mecanismos legales suficientes para desviar el conflicto a la solución más adecuada. El desarrollo legislativo de la reforma se constituye como una oportunidad para estructurar el sistema penal colombiano con base en un concepto de víctimas amplio, pluralista, que desvele la maldad radical de la barbarie del delito y ponga de presente que las víctimas son una realidad que introducen un elemento fundamental en un Estado Social y Democrático de Derecho: son el camino para cualquier solución ${ }^{38}$.

Varias son las etapas que el concepto de victimas ha recorrido hasta llegar al texto que contiene el proyecto que cursa en el Congreso de la República y que de ser aprobado como está resultaria contrario al espiritú que orientó la redacción del acto legislativo 03 de 2002.

En primer lugar, encontramos el texto incluido en el Anteproyecto de Código de Procedimiento Penal elaborado por J. E. Granados Peña, J. A. Sampedro Arrubla, J. D. Riveros Barragan Y M. Hartmann Arboleda, el cual sirvió de base a buena parte de los trabajos de la Comisión Constitucional Redactora ${ }^{39}$; en él se incluyó en el artículo 90 el siguiente concepto:

- "Artículo 90. Víctimas de delito. Se entiende por víctimas a las personas que, individual o colectivamente, hayan sufrido algún daño como consecuencia de acciones u omisiones que violen la ley penal.

- Igualmente, son víctimas los familiares o personas a cargo que tengan relación con la víctima directa y las personas que hayan sufrido daños al intervenir para asistir a la víctima en peligro o prevenir la victimación.

- La condición de víctima se tiene con independencia de que se identifique, aprehenda, enjuicie o condene al perpetrador e independientemente de la relación familiar entre el perpetrador y la víctima”.

38 Cfr. Antonio Beristain Ipiña, Victimología. Nueve palabras clave, Ed. Tirant Lo Blanch, Valencia, 2000,. P. 458.

39 Jaime Enrique Granados Peña; Julio Andrés Sampedro Arrubla; Juan David Riveros Barragán; Mildred Hartmann Arboleda,. Anteproyecto de Código de Procedimiento Penal, Bogotá D.C., 2003. 
Este concepto tiene como fundamento diversos documentos internacionales (entre los cuales pueden mencionarse la Resolución 40/34 de la Asamblea General de Naciones Unidas, la Declaración sobre Justicia y Asistencia para las víctimas de la Sociedad Internacional de Victimología y la Decisión Marco de la Unión Europea de marzo 15 de 2001 relativa al estatuto de la víctima en el proceso penal), apuesta en sus dos primeros incisos por un concepto democrático y pluralista; y en el tercer inciso fundamenta la condición de víctima no en la condena probable al imputado, sino en el sufrimiento del otro, de las víctimas, como una forma de aceptar nuestra responsabilidad, como seres humanos y como sociedad, en remediarlo. Así lo hace ver M. T. De La GARZA, cuando escribe que los principios de una sociedad justa, la democracia y la igualdad son necesarios pero no suficientes. Necesitamos también de la permanente preocupación por el bien ajeno que nos lleva más allá de la pura igualdad ya que, sin dicha preocupación, la democracia puede convertirse en una máscara tras la que se esconde y se reproduce la violencia cometida contra los débiles, las víctimas, los excluidos ${ }^{40}$.

El texto trascrito fue sometido a discusión en la sesión de la Comisión del 9 de mayo de $2003^{41}$ efectuando algunos cambios parciales sugeridos en sesiones anteriores, en especial con relación, por una parte con el cambio de el término "Victimas del delito» por el de «Víctimas del Injusto» y el de «perpetrador» por el de "Autor del Injusto», y por la otra con la inclusión de un cuarto inciso en el que se decía expresamente que el término persona utilizado se refería también a las personas jurídicas, organizaciones, asociaciones, comunidades o al Estado ; en concreto el texto sometido a la Comisión fue el siguiente:

- Artículo 86. Víctimas del injusto. Se entiende por víctimas a las personas que individual o colectivamente hayan sufrido algún daño como consecuencia de acciones u omisiones que violen la ley penal.

- Igualmente son víctimas los familiares o personas a cargo que tengan relación con la víctima directa y las personas que hayan sufrido daños al intervenir para asistir a la víctima en peligro o prevenir la victimización.

- La condición de víctima se tiene con independencia de que se identifique, aprehenda, enjuicie o condene al autor del injusto e independientemente de la relación familiar entre éste y la víctima.

- Cuando corresponda, el término persona se referirá a personas jurídicas, organizaciones, asociaciones, comunidades o al Estado.

\footnotetext{
40 María Teresa de La Garza, Política de la Memoria. Una mirada sobre Occidente desde el margen, Editorial Anthropos, Barcelona 2002, p. 21,

41 Acta No. 16.
} 
La discusión final de este artículo se dio en la mencionada sesión de la Comisión, según consta en al acta No. 16, en los siguientes términos ${ }^{42}$ :

- «El doctor Sampedro indicó que en atención a solicitud de la comisión, en el último inciso se agregó al Estado dentro del término persona.

- El doctor Delgado Maya propuso que se cambiara la expresión "corresponderá" por "comprenderá", sugerencia aceptada por la comisión.

- El doctor Rómulo González de igual manera, propuso se agregara "comprenderá, además de aquellos entes con personería jurídica legalmente reconocida".

- El doctor Adolfo Salamanca Correa preguntó por qué se define o especifica quienes son persona. Al respecto el doctor González explicó que conforme al código civil se hacen estas diferenciaciones en atención a los fines que llevan a su constitución.

- Señaló el doctor Salamanca Correa que no ve la necesidad de la citada especificación y por tanto solicitó que se suprimiera el inciso.

- El doctor Delgado Maya sugirió se modificara el artículo 86 en su parte inicial y se establezca que "las personas individuales, colectivas o jurídicas que hayan sufrido un daño...”. Propuesta con la que estuvo de acuerdo la doctora Zuleta.

- Por su parte, el doctor Gómez Velásquez señaló que cuando el código civil hace mención al término persona sin calificarla hace referencia a personas naturales.

${ }^{42}$ Según el Acta No. 16 a esta sesión asistieron como Miembros de la Comisión: Luis Camilo Osorio, Fiscal General de la Nación. María Margarita Zuleta, Viceministra de Justicia. Carlos Arturo Gómez Pavajeau, Viceprocurador General de la Nación. Hugo Quintero Bernate, Delegado del Presidente de la Sala Penal, de la Corte Suprema de Justicia. Temístocles Ortega Narváez, Presidente del Consejo Superior de la Judicatura. Carlos Eduardo Mejía, Defensoría del Pueblo. José Francisco Delgado Maya, Delegado del H. Representante Eduardo Enríquez Maya. Jesús Ignacio García, H. Representante a la Cámara. Gustavo Gómez Velásquez, Académico. adolfo Salamanca Correa, Académico. Jaime Enrique Granados, Académico. Darío Garzón, Delegado del H. Senador Germán Vargas Lleras. Asistieron a esta reunión como invitados especiales y asesores: Rómulo GonzÁlez, Ex Ministro de Justicia; Alfonso Guarín Ariza, Magistrado Sala Administrativa del Consejo Superior de la Judicatura; Luis Fernando Marín Molina, Profesional Especializado de la Dirección de Ordenamiento Jurídico del Ministerio del Interior y de Justicia; Julio AndRÉs SAMPEDRo, Asesor Corporación Excelencia en la Justicia; Mauricio GonzÁlez Cuervo, Director Ejecutivo Corporación Excelencia en la Justicia; Marco Antonio Rueda Soto, Fiscal Delegado ante la Corte Suprema de Justicia; Luis Edgar Martínez, Fiscal Delegado ante la Corte; Guillermo Mendoza, Fiscal Delegado ante la Corte; Ramiro Alonso Marín VÁsquez, Fiscal Delegado ante la Corte; Luz Adriana Camargo, Fiscal Delegada ante la Corte; Oscar Iván Hernández Salazar, Asesor Fiscal General de la Nación; Ana Melba Mogollón, Asesora del Dr. Adolfo Salamanca; Aníbal Fernández de Soto, Asesor del H. Representante Roberto Camacho; Alfredo ArizA, Procurador Cuarto Delegado Casación Penal; Juan David Riveros, Asesor Corporación Excelencia en la Justicia; Clara CAmpo, Asesora Corporación Excelencia en la Justicia; Jesús Monroy, Asesor del Fiscal General de la Nación; Jorge Parra, Asesor del H. Representante Jesús Ignacio García; Consuelo MÉndez, Asesora del Fiscal General de la Nación; Diana Pacheco, Secretaria Privada Fiscal General de la Nación; Cecilia Peña, Asesora del Despacho del Fiscal General de la Nación; Rodrigo Martinez, Secretaría Técnica Corporación Excelencia en la Justicia; Liliana Beayne, Secretaría Técnica, Corporación Excelencia en la Justicia. 
- El doctor Gómez Pavajeau manifestó que de igual manera se entendía en la Constitución.

- El doctor Granados señaló que, de acuerdo a la Constitución, el término persona incluye hasta el nasciturus, por tanto ésta no se debe tener como único referente. De otro lado, indicó, en lo relativo a las personas jurídicas, que si el Estado es considerado persona jurídica sobraría el último inciso.

- La Presidencia puso en consideración la propuesta del doctor Delgado Maya: "se entiende por víctimas las personas naturales o jurídicas que individual o colectivamente hayan sufrido algún daño como consecuencia de..." y la eliminación del último inciso.

- El doctor Rómulo González propuso nuevamente que se incluyera los entes con personería jurídica reconocida. Agregó que la persona jurídica, según dice el código, son las fundaciones y corporaciones reconocidas por la ley y existen otras como los sindicatos que sin ser personas jurídicas, gozan de personería jurídica reconocidas por la ley.

- Por su parte, el doctor Mauricio González Cuervo explicó que existe un concepto mas comprensivo al de persona, que es el de sujetos de derecho, ya que las personas naturales y jurídicas son sujetos de derecho, y existen otras como los patrimonios afectos a un fin que, por no tener personería jurídica pero si tener un fin específico les permite gobernar derechos subjetivos. Agregó, que el Estado es persona pública, y por tanto es persona jurídica, de la cual dependen los ministerios. Ahora bien los sujetos de derecho son titulares de derechos singulares o colectivos, en ese sentido, consideró pertinente que se establezca: "que las personas o sujetos de derecho, individual o colectivamente hayan sufrido un daño" es decir en cuanto a titulares de derechos singulares subjetivos o derechos subjetivos colectivos.

- En este punto el doctor Gómez Pavajeau manifestó que se está dejando por fuera las embajadas, consulados, es decir, los organismos internacionales, los cuales también son sujetos de derechos.

- Sugirió el doctor Granados la siguiente redacción: "se entiende por víctimas a las personas naturales o jurídicas y demás sujetos de derechos individuales o colectivamente hayan sufrido algún daño como consecuencia de acción u omisión de la ley penal".

- Por su parte, el doctor Guarín, manifestó que la última redacción propuesta es suficiente y si por algún motivo se presenta una dificultad, se podría agregar que también al Estado.

- Para el doctor Mendoza es importante dejar claro el concepto pues en caso de una eventual reparación a favor de la víctima, es necesario dejar conocer 
quien tiene derecho y a nombre de quien se van a hacer los reclamos económicos derivados de esa condición de víctima.

- A su turno, el doctor Sampedro propuso la siguiente redacción: "Se entiende por víctimas a las personas naturales o jurídicas y demás sujetos de derechos que individual o colectivamente hayan sufrido algún daño como consecuencia de acciones u omisiones que violen la ley penal.

- La comisión aprobó por unanimidad el artículo modificado de acuerdo a la propuesta del doctor Sampedro y la eliminación del último inciso».

El artículo aprobado por unanimidad por la Comisión Constitucional redactora se concretó en el siguiente texto:

Artículo. Se entiende por víctimas a las personas naturales o jurídicas y demás sujetos de derechos que individual o colectivamente hayan sufrido algún daño como consecuencia de acciones u omisiones que violen la ley penal.

- Igualmente son víctimas los familiares o personas a cargo que tengan relación con la víctima directa y las personas que hayan sufrido daños al intervenir para asistir a la víctima en peligro o prevenir la victimización.

- La condición de víctima se tiene con independencia de que se identifique, aprehenda, enjuicie o condene al autor del injusto e independientemente de la relación familiar entre éste y la víctima.

Con todo, esta no fue la redacción que se presentó al Congreso de la República, alguien modificó abusiva y sustancialmente el texto limitandolo en sus alcances y rompiendo la estructura victimológica del proyecto. El texto que hoy cursa en el Congreso es del siguiente tenor:

Artículo 92. Víctimas. Se entiende por víctimas, para efectos de este código, las personas naturales o jurídicas y demás sujetos de derechos que individual o colectivamente hayan sufrido algún daño directo como consecuencia del injusto.

- La condición de víctima se tiene con independencia de que se identifique, aprehenda, enjuicie o condene al autor del injusto e independientemente de la relación familiar entre éste y la víctima.

Finalmente, este fue el concepto que se defendió en las discusiones en el Congreso de la República y a la postre aprobado como el Artículo 132 del nuevo Código. El cambio hace regresar al sistema penal a un concepto limitado de víctimas, pues incluye en el inciso primero la palabra «directo» y suprime de un tajo el inciso segundo, generando en la norma un vicio de inconstitucionalidad no solo por la modificación que se introduce que no fue discutida ni aprobada por la Comisión Constitucional Redactora, sino porque con ella se aparta sustancialmente 
del espíritu que orientó la reforma contenida en el Acto Legislativo 03 de 2002 y que hoy hace parte de nuestra Constitución Política.

Con el texto contenido el artículo 132 del nuevo C.P. de P. se apuesta por la visión del vencedor, desarticula la reforma en materia de víctimas y el avance que se había dado con la modificación constitucional en busca de un esquema procesal más humano se afecta sustancialmente, con lo cual el interrogante planteado al comienzo de este apartado habría que responderlo negativamente. Con todo, es de resaltar que el Acto legislativo ha puesto las bases constitucionales para implementar en futuras reformas un sistema que haga una verdadera apuesta por las víctimas del delito. Tres aspectos confirman lo dicho:

En primer lugar, se ha consagrado, por primera vez en la historia penal de Colombia un catálogo de derechos para las víctimas en la actuación penal, el cual se había discutido en la Comisión Preparatoria y presentado como anexo al proyecto de Acto Legislativo ${ }^{43}$. Esta carta de derechos de las víctimas se concreta en:

1. A recibir, durante todo el procedimiento, un trato humano y digno.

2. A la protección de su intimidad, a la garantía de su seguridad, y a la de sus familiares y testigos a favor.

3. A una pronta e integral reparación de los daños sufridos, a cargo del autor o partícipe del injusto o de los terceros llamados a responder en los términos de este código.

4. A ser oídas y a que se les facilite el aporte de pruebas.

5. A recibir desde el primer contacto con las autoridades y en los términos establecidos en este código, información pertinente para la protección de sus intereses y a conocer la verdad de los hechos que conforman las circunstancias del injusto del cual han sido víctimas.

6. A que se consideren sus intereses al adoptar una decisión discrecional sobre el ejercicio de la persecución del injusto.

7. A ser informadas sobre la decisión definitiva relativa a la persecución penal; a acudir, en lo pertinente, ante el juez de control de garantías, y a interponer los recursos ante el juez de conocimiento, cuando a ello hubiere lugar.

8. A ser asistidas durante el juicio y el incidente de reparación integral, si el interés de la justicia lo exigiere, por un abogado que podrá ser designado de oficio.

9. A recibir asistencia integral para su recuperación en los términos que señale la ley.

10.A ser asistidas gratuitamente por un traductor o intérprete en el evento de no conocer el idioma oficial, o de no poder percibir el lenguaje por los órganos de los sentidos.

${ }^{43}$ Cfr. Acta No. 4, sesión de febrero 18 de 2002. 
Esta carta de derechos se complementa con la evolución de la jurisprudencia constitucional, especialmente las sentencias C-228 de 2002 M.P. MAnuel JosÉ Cepeda / Eduardo Montealegre Lynett y T-249 de 2003 M.P. Eduardo Montealegre Lynett, y el artículo 137 del C. P. de P. que establece algunas reglas para la intervención de las víctimas en la actuación, dejando claro que éstas son unOS ALIADOS INDISPENSABLES en la labor del fiscal e intervienen activamente en la persecución del delito al lado del Fiscal y en el juicio como sujetos procesales en garantía de sus derechos a LA VERDAD, LA JUSTICIA Y LA REPARACIÓN.

Sin embargo, el mencionado art. 137 num. 4 establece, de manera absolutamente incoherente, que en caso de existir pluralidad de víctimas, el fiscal, durante la investigación, solicitará que éstas designen hasta dos abogados que las represente. De no llegarse a un acuerdo, el fiscal determinará lo más conveniente y efectivo. Este numeral es claramente inconstitucional en la medida en que está negando la participación de todas las víctimas en la investigación, no en el juicio, contrariando así estándares internacionales y la propia constitución que buscó siempre que la intervención de las víctimas en la investigación se hiciera directamente y sólo en el juicio fuera limitada ${ }^{44}$.

En segundo lugar, el Acto Legislativo en el anexo de bases ideologicas ${ }^{45}$, luego de una ardua discusión, creo la figura del defensor de oficio para las víctimas, la cual fue desarrollada por el nuevo C. de P.P. Con esta figura el proceso penal colombiano se coloca a vanguardia en el derecho comparado en protección y asistencia a las víctimas, pues mientras que el imputado siempre tiene derecho a un abogado, las víctimas no suelen recibir ninguna asistencia legal ${ }^{46}$.

No deja de sorprender, por decir lo menos, la posición asumida por la Defensoría del Pueblo en la Comisión Preparatoria, en el seno de la cual manifiestó una "objeción total" para asumir el tema de la protección judicial de las víctimas. En efecto, en la discusión del artículo 15, que hacía parte del documento de Bases Ideológicas, el cual determinaba que el Estado, a través del Sistema Nacional de Defensoría Pública, debía proporcionar, cuando el interés de la justicia lo exija, los servicios de un apoderado judicial mediante el cual se respete el debido proceso y el derecho de las víctimas a la obtención de una reparación integral, y se le asignaba la responsabilidad al Defensor del Pueblo de velar porque se le daría cabal cumplimiento a la carta de derechos de las víctimas, la posición de la Defensoría del Pueblo fue tajantemente manifestada a través de uno de los de-

44 Cfr. Anteproyecto de Código de Procedimiento Penal, Ob. Cit., artículo 404; Acta No. 4, sesión de febrero 18 de 2002

${ }^{45}$ Cfr. Acta No. 4, citada.

46 Cfr. Vicente Garrido, Per Stangerland, Santiago Redondo. Principios de Criminología, Ed. Tirant Lo Blanch, Valencia, 1999, p. 680. 
legados del Defensor del Pueblo, la Dra. Karin KUHFELDT, en los siguientes términos:

"Hay una objeción total de la Defensoría del Pueblo en asignarle además de la representación judicial de los procesados, el tema de la protección judicial de las víctimas. Sería un problema, entre otras cosas, para la Escuela de Capacitación de la Defensoría, además de que no podría responder por tantas funciones.... $\rangle^{47}$

Una posición como la expresada pone de presente la necesidad de emprender una reflexión profunda sobre el sentido, orientación y fundamento de muchas de las instituciones que nacieron con la Constitución de 1991 y que hoy, después de más de diez años, arrojan un balance verdaderamente negativo frente a los objetivos para los que fueron creadas. Tal es el caso de la Defensoría del Pueblo, ocupada más en la defensa de los victimarios que de las víctimas para quienes fue creada; no se puede ignorar que al Defensor del Pueblo le está encomendada la función general de velar por la promoción, el ejercicio y la divulgación de los derechos humanos ${ }^{48} \mathrm{y}$ esta función debe concretarse, en un país con los índices de victimación de Colombia, fundamentalmente en las víctimas.

Finalmente, en tercer lugar, es de resaltar la consagración constitucional de la llamada Justicia Restaurativa y su posterior desarrollo den el C. de P.P.. En la reunión de la Comisión Preparatoria de la Reforma Constitucional para la implementación de un Sistema de orientación acusatoria que se llevó a cabo en la Fiscalía General de la Nación el día 6 de marzo de 2002, se decidió incluir, en el texto que se propuso al Congreso de la República, el tema de la Justicia Restaurativa para ser implementado legalmente ${ }^{49}$; posteriormente, luego de los ocho debates legislativos que se exigen para la aprobación de una reforma constitucional, el Congreso de la República aprobó un texto de Acto Legislativo en el que, en el artículo 9 que modificó el 250 de la Constitución Política, se dispuso: «La ley fjará los términos en que podrán intervenir las víctimas en el proceso penaly los mecanismos de justicia restaurativa».

Con esta decisión se incluyó por primera vez en la Constitución el término Justicia Restaurativa, el cual ha dado lugar a un gran debate académico nacional, no siempre con el rigor que el tema exige, acerca de ¿Qué es y para qué sirve la Justicia Restaurativa? Si bien es cierto, el mundo lleva años estudiando el tema y

47 Acta $\mathrm{N}^{\circ} 4$, citada.

48 Cfr. Artículo 282 de la Constitución Política.

49 Acta No. 7, Sesión de marzo 6 de 2002, Cfr. Reforma Constitucional de la Justicia Penal. Actas de la Comisión Preparatoria y Documentos de Trámite Legislativo, Tomo I, Ob. Cit., p. 131 a 154. 
en Colombia se han implementado diversos programas que pudieran calificarse como restaurativos, es solo a partir de la expedición del Acto Legislativo 03 de 2002 que se aborda sistemáticamente el tema y surge la necesidad de encausar el debate académico para no perder una oportunidad histórica de aportar una cosmovisión más humana del sistema penal.

La justicia Restaurativa es un movimiento en el campo de la victimología y la criminología que apunta a reconocer que la conducta punible causa daños concretos a las personas y las comunidades e insta a que la justicia repare efectivamente esos daños y a que tanto la comunidad como las partes en conflicto se les permita participar en el proceso de su solución. Los programas de justicia restaurativa, por consiguiente, habilitan a las víctimas (quienes deben tener una total participación en orden a la reparación), al infractor y a los miembros afectados de la comunidad para que estén directamente involucrados en dar una respuesta al delito. El proceso restaurativo debe involucrar a todas las partes como aspecto fundamental para alcanzar el resultado restaurador de reparación y paz social.

La Organización de las Naciones Unidas (ONU) enfatiza estos aspectos al establecer que por programa de Justicia Restaurativa se entiende todo programa que utilice procesos restaurativos e intente lograr resultados restaurativos, entendiendo por proceso restaurativo todo proceso en que las víctimas, el delincuente y, cuando proceda, cualesquiera otras personas o miembros de la comunidad afectados por un delito, participen conjuntamente de forma activa en la resolución de cuestiones derivadas del delito, por lo general con la ayuda de un facilitador; y por Resultado Restaurativo debe entenderse un acuerdo alcanzado como consecuencia de un proceso restaurativo cuyo contenido sea la reparación, la restitución y el servicio a la comunidad, encaminados a atender a las necesidades y responsabilidades individuales y colectivas de las partes en conflicto y a lograr la reintegración de las víctimas y el delincuente ${ }^{50}$.

En este orden de ideas, podemos sostener que la Justicia Restaurativa constituye una forma alternativa de ver el sistema penal que, sin menoscabar el derecho del Estado en la persecución del delito, busca, por una parte, ver los actos criminales en forma más amplia en vez de defender el crimen como simple trasgresión de las leyes, reconoce que los infractores dañan a las víctimas, comunidades y aun a ellos mismos; y por la otra, involucrar más partes en repuesta al crimen, en vez de dar papeles clave solamente al estado y al infractor, incluye también víctimas

50 Organización De Naciones Unidas (ONu), Principios básicos de la utilización de programas de justicia restaurativa en materia penal, en Informe de la reunión del grupo de expertos sobre justicia restaurativa, Comisión de Prevención del delito y justicia penal, 11 período de sesiones, Viena 16 a 25 de abril de 2002. Se puede consultar en: http: //www.unodc.org/pdf/crime/commissions/11 comm/sadd1s.pdf. 
y a la comunidad. En pocas palabras, la Justicia Restaurativa, mide en forma diferente el éxito frente al conflicto, en vez de medir cuanto castigo fue infringido, establece si los daños son reparados o prevenidos ${ }^{51}$.

La justicia restaurativa tiene como punto de partida el reconocimiento de que las víctimas son una realidad presente que nos habla de las injusticias del pasado y nos obliga a tomar en cuenta sus derechos como el camino obligado a seguir para la construcción de una sociedad más humana, es el fundamento para pensar en una propuesta alternativa que permita el diseño de una justicia de las víctimas sin venganza que ponga su mirada en el sufrimiento de los inocentes, en la reparación del daño ocasionado voluntariamente, la proyecte como un valor superior y condición ineludible de la paz ${ }^{52}$.

Se trata de una aproximación a la justicia de las víctimas, lo que conduce a la construcción de una justicia que tenga en cuenta el pasado, una justicia anamnética ${ }^{53}$ que nos comunique una experiencia a través del encuentro que se hace posible en el proceso penal, una experiencia histórica del mal radical que lucha para evitar la repetición de este ${ }^{54}$.

La ausencia del pasado hace insuficiente el presente e impide la construcción de un futuro diferente, novedoso, que no sea la simple repetición del presente. Como sostiene J. C. MELICH, ante los acontecimientos del pasado y del presente no se puede seguir como si nada hubiera sucedido. La filosofía ni puede ni debe legitimarlos, está obligada a decir «no», a «negar», a «criticar». Toda filosofía, toda acción pedagógica, toda política social y jurídica debe estar comprometida con los acontecimientos del presente, con los acontecimientos de Barbarie y está obligada a la transformación social, a la solidaridad y a la responsabilidad con los marginados, los humillados, los vencidos ${ }^{55}$.

Esta forma de imaginar la justicia hace que el proceso, de ser un espacio irreal, deshumanizado y excesivamente dogmatico, pase a ser un escenario para el encuentro víctima-victimario, un espacio para el testimononio que creativamente enlaza la experiencia pasada y la presente, y la proyecta a un futuro para que el

51 Si hay una historia, si hay un tiempo, escribe JoAn-Carles Mèlich, Filosofia de la Finitud, Editorial Herder, Barcelona 2002, p. 43, quiere decir también que hay otras historias posibles, otros mundos. El ser humano es finito porque vive en un mundo, en una interpretación, pero desde esta interpretación puede imaginar otros mundos, mundos diferentes, alternativos.

52 La justicia recreativa, escribe A. BERISTAIN IPIÑA, Justicia Restaurativo-Agápica, no vindicativa, palabras de agradecimiento en el Acto Académico de imposición de la Gran Cruz de San Raimundo de Peñafort, en Eguzkilore, Cuaderno del Instituto Vasco de Criminología, No. 15, San Sebastián, 2001, no pretende hacer sufrir al victimario, pero sí que éste reconozca su crimen, y restaure el perjuicio causado a las víctimas directas e indirectas.

53 Cfr. Marta Tafalla, Theodor W. Adorno. Una filosofia de la memoria, Ed. Herder, Barcelona, 2003, p. 202 y ss.

54 Cfr. Joan-Carles Mèlich, Filosofia de la Finitud, Ob. Cit.

55 Joan-Carles Mèlich. Totalitarismo y Fecundidad. La Filosofía frente a Auschwitz, Ob. Cit., p. 93. 
pasado no quede en el olvido, y para que aquel que recibe la experiencia pueda rehacerla y aprender de ella.

Esta dimensión pedagógica del espacio judicial exige volver la mirada al otro, a las víctimas y a los victimarios como protagonistas indispensables de una relación ética, una relación de compasión y de responsabilidad, en la que se acojan mutuamente; a priori, escribe J. C. MÉLICH, el otro no es ni una amenaza, ni un amigo, sino que en cada momento, en cada instante, puede llegar a ser amigo o enemigo $^{56}$.

En este orden de ideas, la Justicia Restaurativa busca acercarnos a esa visión inedita de la justicia en la que sin pretender hacer sufrir al victimario, este reconozca su crimen, y restaure el daño causado a las víctimas directas e indirectas; llama la atención acerca de la necesidad de diferenciar entre venganza y justicia, dos conceptos con los que existe, especialmente en sociedades como la colombiana, una tentación irresistible a tratar como sinónimos, sin embargo, como lo plantea R. MATE, las diferencias son sustanciales, la justicia pone su mirada en la víctima, en el daño objetivo que se le ha hecho, planteandose la reparación del daño. La venganza, por el contrario, tiene en punto de mira al verdugo y lo que busca es hacérselas pasar a él tan mal como él se lo ha hecho pasar a la víctima. De esta manera, cuando la sanción al culpable pierde su objetivo de justicia (reparar el daño, impedir que este se repita, resocializar al delincuente), hacer justicia se convierte en un acto de venganza ${ }^{57}$.

En síntesis, pensar la justicia en una dimensión restaurativa significa reconocer a las victimas como protagonistas del delito, el cual, sin dejar de considerarse como una conducta que pone en peligro o vulnera un bien tutelado por el Estado, se consedera primordialmente como un conflicto humano que requiere ser superado, no mediante el castigo sino por la sanción constructiva , cono escribe A. BERISTAIN, no de la nada, sino desde la cosa dañana; desde y con las ruinas ${ }^{58}$. La justicia restaurativa apunta a la idea del delito como una oportunidad para la construcción de nuevas relaciones entre las partes involucradas, es una justicia desde y hacia las víctimas que tiene en cuenta el pasado, que busca reconocerlo, regresar a él, pero no para instalarse en el dolor, sino para reconocer que se ha cometido una injusticia (que allí hay derechos pendientes), y a partir de allí visualizar el futuro.

${ }^{56}$ Cfr. Joan-Carles Mèlich, Filosofia de la Finitud, Ob. Cit., p. 48.

57 Cfr. Reyes Mate. En torno a una Justicia Anamética, en La ética ante las víctimas, Ed. Anthropos, Madrid. 2003, p. 101.

${ }^{58}$ Antonio Beristain IpiÑa, Criminología, Victimología y Cárceles, Tomo I, Editorial Pontificia Universidad Javeriana, Fac. Ciencias Jurídicas, Colección Profesores No. 22, Bogotá D.C., 1996, p. 274. 
Una justicia que tenga en cuenta el pasado, siguiendo a R. MATE ${ }^{59}$, significa:

En primer lugar, responder a una sensibilidad nueva. Esto es una justicia que desborde los estrechos límites del tiempo y del espacio en los que permanecía encerrada. Desde esta perspectiva aparece el proceso contra Pinochet, el de los militares argentinos, y, al menos simbólicamente, la creación de una Corte Penal Internacional, en los cuales la justicia a ha buscado trascender los límites territoriales y temporales de la justicia; son casos que nos han enseñado que hay atropellos que comprometen la existencia misma de la especie animal y vegetal e implican daños irreversibles para humanidad. En este sentido, señala R. MATE, dos medidas que han marcado un paso gigante en la historia moral del derecho, el Juicio de Nüremberg a los criminales Nazis y la Ley que en 1964 votó el Parlamento francés declarando la imprescriptibilidad de los crímenes contra la humanidad.

Este desborde espacial y temporal de la justicia, aun con la dificultad que supone tomar la decisión acerca de la imprescriptibilidad de sólo determinados crímenes, señala el despertar de una sensibilidad nueva respecto a la responsabilidad actual de crímenes pasados que va en aumento ${ }^{60}$.

En segundo lugar, la justicia de las víctimas significa entender la justicia como respuesta a la experiencia de la injusticia, es decir, remitirse a los hechos, escuchar los gritos o el duelo que causa el sufrimiento humano; esta experiencia subyace a toda la elaboración de la teoría de la justicia, de tal manera que para llegar ahí, procede partir de la experiencia de injusticias procesada por la humanidad a lo largo de los siglos en el lenguaje ${ }^{61}$; sin embargo, es de tener en cuenta que, el lenguaje humano conlleva una deficiencia, y es que resulta insuficiente para nombrar las cosas, es decir, no puede aproxiamarnos a ellas mas que a tientas, mediante conceptos, permitiendo solo una aproximación a la singularidad del individuo, a sus circunstancias, en forma global.

Con todo, la experiencia, para ser viva, nos dice J. C. MÈLICH ${ }^{62}$, tiene que poder ser transmitida, para lo cual se necesita del testimonio, pues el que da testimonio enlaza la experiencia pasada y la presente, y la abre a un futuro para que el pasado no quede en el olvido, y para que aquel que recibe la experiencia pueda rehacerla y aprender de ella ${ }^{63}$.

\footnotetext{
${ }^{59}$ Reyes Mate. En torno a una Justicia Anamética, Ob. Cit., p. 101.

${ }^{60}$ Cfr. Reyes Mate. En torno a una Justicia Anamética, Ob. Cit., p. 105/106.

${ }^{61}$ Cfr. Reyes Mate. En torno a una Justicia Anamética, Ob. Cit., p. 107.

${ }^{62}$ Cfr. Joan-Carles Mèlich, Filosofia de la Finitud, Ob. Cit.

${ }^{63}$ «No obstante, escribe Joan-Carles Mèlich, Filosofia de la Finitud, Ob. Cit., p. 109, el testimonio, como todo aquello que afecta a los seres humanos, puede pervertirse. Dar testimonio puede llegar a ser un dar ejemplo. Creo que el ejemplo es la perversión del testimonio. El que da ejemplo se pone a sí mismo como modelo... En la acción de testimoniar, en cambio, resulta mucho más importante la experiencia y, sobre todo, la revisión de la experiencia por parte del que la recibe. Para aquél que verdaderamente da testimonio, el otro es mucho más importante que el propio yo».
} 
Por último, en tercer lugar, la justicia de la víctimas descubre que hay dos visiones de la realidad: la de los vencedores y la de los vencidos. Para los vencedores, afirma R. MATE, la suspensión de los derechos, el tratamiento del hombre como nuda vida, es decir, todo lo que el estado de excepción conlleva, es una media excepcional, transitoria, conducente al control y superación de un conflicto; mientras que para las víctimas esa excepcionalidad es la regla, siempre han vivido así, suspendidos en sus derechos y marginados en la historia. Lo coherente es construir un concepto de historia en torno a esa experiencia de injusticia permanente, romper con ese continum opresor y declarar el verdadero estado de excepción al estado real de excepción ${ }^{64}$.

En concreto, con una justicia de las víctimas, como lo es un modelo restaurativo, de lo que se trata es de ver el mundo de manera invertida, con los ojos de las victimas que desvelan el sufrimiento humano y nos advierten que allí hay derechos que el sistema penal ha dejado pendientes y mientras no se atiendan nada impide que la barbarie del delito se repita; el silencio del hombre, su indiferencia ante la victimación, enferma, impide escuchar el estruendo de la barbarie y ahoga la voz de las víctimas que reclaman por sus derechos pendientes; por ello, con la justicia de las víctimas se impone una estrategia que permita repensar conceptos, como el de víctimas del delito, sobre los que se fundamenta el sistema penal para hacerlos más comprensivos a fin que posibiliten una justicia pluralista y más humana.

Lo dicho hasta este momento deja claro que la Justicia Restaurativa tiene como fundamento una opción preferencial por las víctimas que franquea todo el sistema de administración de justicia en busca de la construcción de un espacio para el encuentro víctima-victimario, no solo desde la diferencia, sino desde la deferencia ${ }^{65}$; un encuentro creativo que se constituya como una oportunidad desde la que se pueda responder a las víctimas y por las víctimas, y que, mediante una estrategia basada en la verdad, la justicia y la reparación, apunte a la reconstrucción del tejido social roto por el delito.

En este orden de ideas, el nuevo C. de P. P., sin pretender agotar el tema consagró, en los arts. 518 a 521, los principios generales, siguiendo para ello los criterios de Naciones Unidas. Así estableció como principios:

1. El delito constituye en primer lugar una ofensa contra las víctimas: es un conflicto que genera oportunidades

64 Cfr. Reyes Mate. En torno a una Justicia Anamética, Ob. Cit., p. 108.

${ }^{65}$ «Ser deferente, escribe Joan-Carles Mèlich, Filosofia de la Finitud, Ob. Cit. P. 114, es responder al otro y del otro, responsabilizarse del otro que no tiene poder. Para ser deferente es necesario romper el imperialismo de lo económico e instaurar el tiempo, tener presente el tiempo. En la deferencia, el tiempo es el otro, el tiempo es para el otro» 
2. Se pueden utilizar antes de la investigación, durante la investigación, en la fase dosificación de la pena y en el incidente de reparación.

3. Se deben utilizar con el consentimiento libre y voluntario de las víctimas y de los victimarios.

4. La participación del imputado no se utilizará como prueba de admisión de culpabilidad en procedimientos judiciales posteriores.

5. Las victimas como los victimarios deben poder consultar un abogado en relación con el proceso restaurativo.

6. Las partes en un proceso restaurativo deben estar plenamente informadas de sus derechos, de la naturaleza del proceso y de las consecuencias de la decisión que tome.

7. Los acuerdos que se produzcan deben ser incorporados a decisiones o sentencias judiciales.

8. El incumplimiento de un acuerdo no deberá utilizarse como fundamento para una condena.

En cuanto a los mecanismos el C. de P.P. consagró tres:

La Conciliacion Pre-Procesal que se surtirá obligatoriamente y como requisito de procedibilidad para el ejercicio de la acción penal, cuando se trate de delitos querellables, ante el fiscal que corresponda, o en un centro de conciliación o ante un conciliador reconocido como tal.

La Conciliacion en el Incidente de Reparación la cual se puede producir luego del anuncio del sentido del fallo y que no incluye aspectos estrictamente penales.

LA MEDIACION que procede desde la formulación de la imputación y hasta antes del inicio del juicio oral para los delitos perseguibles de oficio cuyo mínimo de pena no exceda de cinco (5) años de prisión, siempre y cuando el bien jurídico protegido no sobrepase la órbita personal del perjudicado, y víctima, imputado o acusado acepten expresa y voluntariamente someter su caso a una solución de justicia restaurativa.

Si bien es cierto la mediación en la propuesta que se hizo y se aprobó en la Comisión Preparatoria se extendía a la totalidad de los delitos ${ }^{66}$ debe resaltarse como positivo la inclusión de esta figura esencial en el restablecimiento del tejido social roto por el delito y la consecución de la paz social.

\section{Reflexión final}

El estudio y la discusión sobre todos puntos de la reforma al sistema penal colombiano que tienen relación con las víctimas amerita más tiempo del que por

${ }^{66}$ Cfr. Anteproyecto de Código de Procedimiento Penal, Ob. Cit., artículos 476 a 482. 
ahora disponemos. Por el momento nuestra pretensión no es otra que plantear unas inquietudes generales para su estudio y, por ahora, advertir que Colombia atraviesa por un momento trascendental, del que hace parte esencial la implementación de la reforma al Sistema Penal, un período que invita a reflexionar sobre el diseño de instrumentos, más humanos, que hagan posible la búsqueda de la verdad y la justicia como pasos previos para alcanzar la verdadera paz. Una verdad compuesta por realidades agobiantes y crímenes atroces, en la que los culpables pueden seguir como si nada hubiera pasado ante el desconcierto de sus víctimas que, ultrajadas, deben soportar que se les despoje de su dignidad en espera de una justicia que no llegará, ahonda las heridas, intensifica la desazón de la injusticia e impide alcanzar una paz sólida.

Sin lugar a dudas no podemos sostener que en la reforma al sistema penal colombiano hay una verdadera reconstrucción victimológica del sistema penal, sin embargo, sí se han dado los primeros pasos en la construcción de una justicia que en el futuro sea capaz de dar respuesta integral a la experiencia de la injusticia, satisfaga las necesidades y expectativas de las víctimas como una forma que impida repetir la barbare ${ }^{67}$.

En un Estado Social y Democrático de Derecho, como el que pretende ser Colombia, basado en el respeto por la dignidad humana, la justicia y la solidaridad, el reconocimiento de los derechos y la atención a las necesidades de las víctimas del delito debe ser una prioridad para alcanzar la paz, no podemos permitir que se siga interpretando que los innumerables sacrificios pasados y presentes son el precio del futuro. En estos tiempos del olvido, nuestra respuesta no puede ser otra que la de emprender la creación de realidades contrarias, donde sea posible la reconciliación y la convivencia futura, donde por fin se alcance la paz.

${ }^{67}$ Como escribe Reyes Mate, La Razón de los Vencidos, Ob.Cit., p. 216, donde se refleja la falta de reconocimiento de los derechos de las víctimas es en la aceptación de un presente -y sus estructuras- construido sobre los derechos de los vencedores. 
